\title{
The role of glucose lowering agents on restenosis after percutaneous coronary intervention in patients with diabetes mellitus
}

\author{
Chris PH Lexis*1, Braim M Rahel ${ }^{1}$, Joan G Meeder ${ }^{1}$, Felix Zijlstra ${ }^{2}$ and \\ Iwan CC van der Horst ${ }^{2}$
}

\begin{abstract}
Address: ${ }^{1}$ Department of Cardiology, VieCuri Medical Centre, Venlo, The Netherlands and ${ }^{2}$ Department of Cardiology, University Medical Centre Groningen, Groningen, The Netherlands

Email: Chris PH Lexis* - c.lexis@student.unimaas.nl; Braim M Rahel - brahel@viecuri.nl; Joan G Meeder - jmeeder@viecuri.nl; Felix Zijlstra -f.zijlstra@thorax.umcg.nl; Iwan CC van der Horst - i.c.c.horst@thorax.umcg.nl

* Corresponding author
\end{abstract}

Published: 28 July 2009

Cardiovascular Diabetology 2009, 8:4 I doi:10.1 |86/I475-2840-8-4|

This article is available from: http://www.cardiab.com/content/8/I/4 I

(C) 2009 Lexis et al; licensee BioMed Central Ltd.

This is an Open Access article distributed under the terms of the Creative Commons Attribution License (http://creativecommons.org/licenses/by/2.0), which permits unrestricted use, distribution, and reproduction in any medium, provided the original work is properly cited.

\begin{abstract}
Introduction: The prevalence of diabetes is increasing rapidly, and individuals with diabetes are at high risk for cardiovascular disorders. Subsequently the percentage of patients with diabetes subjected to revascularisation, i.e. either percutaneous coronary intervention $(\mathrm{PCl})$ or coronary artery bypass grafting (CABG) also rises rapidly. The outcome of patients with diabetes after $\mathrm{PCl}$ is worse than for patients without diabetes. Restenosis is the main limiting factor of the long-term success of $\mathrm{PCl}$. Although stents and antithrombotics improved outcome after $\mathrm{PCl}$ in both diabetics and non-diabetics, diabetics still have a worse prognosis. This leads to the suggestion that the restenosis mechanism in diabetics might be different from that in non-diabetics.
\end{abstract}

Conclusion: Several glucose lowering agents have been shown to influence the restenosis process and thus the outcome after $\mathrm{PCl}$. Current data of especially metformin and thiazolidinediones indicate beneficial results as compared to insulin and sulfonylurea on restenosis. However, no large trials have been undertaken in which the effect of glucose lowering agents on restenosis is associated with improved outcome.

The purpose of this review is to summarize the effect of diabetes and glucose lowering agents on restenosis.

\section{Introduction}

In patients with diabetes, coronary artery disease (CAD) is often present [1]. In comparison with patients without diabetes, CAD is manifest earlier in life [1]. Especially women with diabetes have a significantly higher risk of developing CAD in comparison with men [2]. The calibre of "normal" coronary arteries at coronary angiography is smaller in patients with diabetes [3]. Diabetics have more multi vessel coronary artery disease and form less often collaterals $[4,5]$. Not only have patients with diabetes more plaques, the plaques are more inflamed and necrotic, forming a risk factor for rupture and therefore myocardial infarction (MI) [6]. After MI diabetics have a worse prognosis $[7,8]$. Patients with type 2 diabetes without known CAD have a risk of a MI comparable to nondiabetics with a previous history of MI [1]. It is therefore 
reasonable that $\mathrm{CAD}$ is accountable for $70-80 \%$ of the diabetes related mortality [7]. Despite improvement of coronary interventions, outcome in patients with diabetes is impaired $[1,8]$. Restenosis is the main limiting factor of the long-term success of percutaneous coronary interventions (PCI) [9]. Possibly the restenosis mechanism in diabetics might be different from that in non-diabetics. The purpose of this review is to summarize the influence of diabetes on coronary restenosis and to summarize the effect of glucose lowering agents on restenosis and outcome.

\section{Mechanism of Disease Restenosis in diabetics}

Diabetes is one of the most important risk factors for restenosis after stent implantation, with odds ratios of 1.9 to 2.5 [10]. Diabetes leads to more extensive neointimal hyperplasia, plaque formation, altered hemodynamics and inadequate compensatory remodeling (table 1) [8]. Restenotic intimal hyperplasia in diabetics differs from non-diabetics $[7,11,12]$. Diabetic vascular smooth muscle cells exhibit increased rates of proliferation, leading to luminal narrowing [11]. Furthermore, restenotic intimal hyperplasia in diabetics has increased macrophage infiltration $[11,12]$, lipid-rich and collagen-rich sclerotic content [8]. Diabetics have more vaso vasorum neovascularisation, leading to intraplaque haemorrhage [12]. Atherosclerotic laesions in diabetics are more prone to rupture [11]. Furthermore, progression of atherosclerotic plaques is accelerated in diabetics [8]. More extensive neointimal hyperplasia and more rapid plaque formation in diabetics leads to more restenosis and less stable atherosclerotic plaques.

Several factors can account for the more extensive CAD in patients with diabetes. First, diabetic patients are more likely to have (co-) morbidities, among which are cardiovascular risk factors such as the metabolic syndrome. According to the National Cholesterol Education Program (NCEP) Expert Panel ATP-III-criteria (2001) the metabolic syndrome consist of 3 or more of 5 risk factors: hyperglycaemia, hypertension, decreased levels of HDL, elevated levels of triglycerides and abdominal (visceral) obesity [13]. The metabolic syndrome is associated with a proinflammatory and prothrombotic state [7].

Several molecular mechanisms have been implicated in hyperglycaemic-induced endothelial damage: activation of protein-kinase $\mathrm{C}$ isoforms, increased hexosamine pathway flux, increased advanced glycation end product formation, increased polyol pathway flux and activation of the proinflammatory nuclear transcription factor kappa-B [7]. All these mechanisms are associated with overproduction of reactive oxygen species, which lead to endothelial dysfunction, decreased vasodilatation and promotion of atherosclerotic plaque formation [7]. Plaque formation is one of the forces behind restenosis.

Peroxisome proliferator activated receptors (PPARs) play an important role in the atherosclerotic process. Especially PPAR-gamma - a subfamily - is potent in reducing plaque inflammation, in inhibiting expression of adhesion molecules and in inhibiting formation of cytokines

Table I: Key processes in restenosis in diabetics; the processes are specified to the elevated $(\uparrow)$ or decreased $(\downarrow)$ factors contributing to the elevated risk of restenosis in diabeticscompared to non-diabetics.

\begin{tabular}{ll}
\hline Influence of 4 Key Factors on Restenosis in Diabetics & \\
\hline Process & Factor \\
\hline Proinflammatory state & $\uparrow$ C-peptide \\
& $\uparrow$ Resistin \\
& $\uparrow \mathrm{CRP}$ \\
& $\uparrow$ II-I2 \\
\hline Prothrombotic state & $\uparrow$ P2Y-receptor \\
& $\uparrow$ Endothelial damage by O2-radicals \\
\hline Accelerated and unstable plaque formation & $\uparrow$ Vascular smooth muscle cell proliferation \\
& $\uparrow$ Macrophage infiltration \\
& $\uparrow$ Lipid-rich \\
& $\uparrow$ Collagen-rich \\
& $\uparrow$ Vaso vasorum neovascularization \\
\hline Haemodynamics & $\downarrow$ \\
& $\begin{array}{l}\uparrow \text { Vessel lumen diameter } \\
\text { Multivessel disease }\end{array}$ \\
& $\uparrow$ Viscosity
\end{tabular}


(e.g. interleukin 12 [IL-12]) [7]. It is known IL-12 is an important factor in the pathophysiology of atherosclerosis and leads to up-regulation of T1-helper response, which is associated with CAD [14]. Wegner et al (2008) demonstrated that IL-12 levels are elevated in type 2 diabetics based on fasting proinsulin due to insulin resistance [14].

Furthermore, insulin resistance leads to upregulation of the P2Y-receptor-pathway, a platelet membrane protein [15].

In patients with diabetes increased levels of C-peptide, a cleavage product of proinsulin, circulate. C-peptide promotes monocyte and T-lymphocyte recruitment into the vessel wall [16]. Walcher et al (2006) showed that in early arteriosclerotic lesions of diabetic subjects, C-peptide colocalized adherent to vascular smooth muscle cells (VSMCs) in the media [16]. C-peptide induced phosphorylation of Src-kinase, as well as activation of the extracellular signal-regulated kinase $1 / 2$ (ERK 1/2) and phosphatidylinositol 3-kinase (PI3K) leading to increased cell proliferation.

Another pathway involved in proliferation of VSMCs is through the effects induced by resistin, an adipokine, which is elevated in diabetes [17]. One study has shown that resistin has a proinflammatory effect on endothelial cells [17]. Calabro et al (2004) showed that VSMC proliferation was induced by resistin [17]. Resistin induces VSMC proliferation through both ERK 1/2 and Akt signaling pathways. Furthermore, On et al (2007) demonstrated that elevated preprocedural serum resistin levels may prove to be a useful biological marker for coronary artery disease and restenosis in patients with type 2 diabetes [18].

\section{Coronary Interventions and Restenosis Coronary stents}

The long-term benefit of balloon angioplasty is mainly limited by restenosis of the treated segment, occurring in one third to half of all treated patients [19]. Restenosis causes recurrent myocardial ischemia and therefore necessitates additional revascularisation [19]. Initially, bare metal stents (BMS) were introduced to overcome flow limiting dissections following balloon angioplasty. In addition it was shown that stents resulted in a lower rate of restenosis and recurrent ischemia. Stents prevent vessel recoil and negative remodeling - important steps in luminal narrowing - and thereby reduce the possibility of restenosis [20]. Intimal hyperplasia, another important step in luminal narrowing, is not prevented by stenting and is the main reason for in-stent restenosis.

Drug-eluting stents (DES) are covered with polymers of immunosuppressive agents e.g. paclitaxel, sirolimus, and zotarolimus, which are progressively eluted the first weeks after implantation. DES treatment in both diabetics and non-diabetics leads to a reduction of target vessel revascularization (TVR) and restenosis after PCI in comparison to BMS [10]. A recent meta-analysis by Stettler et al (2009) demonstrated that in 3852 diabetics and 10947 non-diabetics DES and BMS have comparable hazard ratios for mortality [21]. Furthermore, this study confirmed that DES lead to a decrease in revascularization rates compared with BMS in people both with and without diabetes.

Jensen et al (2009) compared paclitaxel eluting stents and sirolimus eluting stents in 74 diabetics and found that paclitaxel eluting stents had increased lumen reduction [22]. Fröbert et al (2009) compared four types of drug eluting stents in 8,231 patients with diabetes, and found significant differences in restenosis rates, favouring the paclitaxel-eluting stents [23]. However, Lee et al (2009) demonstrated in the Drug-Eluting-Stents in Diabetes (DES-DIABETES) trial with 400 patients that on the longterm the sirolimus-eluting stent lead to a reduction of restenosis, TVR and major adverse cardiac events (MACE) [24]. These results were confirmed by a meta-analysis of 16 randomized trials by Schömig et al (2007) [25].

\section{Bare metal stent versus coronary artery bypass grafting} In non-diabetics there is no difference in mortality between PCI with BMS and coronary artery bypass grafting (CABG) for multivessel disease, whereas in diabetics CABG is thought to have a favourable outcome in comparison with PCI [26]. The Bypass Angioplasty Revascularization Investigation (BARI)-trial (2007) demonstrated that in 1,476 non-diabetics there was no difference between elective PCI and CABG, for both short-term and long-term survival, with a 10 -year mortality rate of $23.0 \%$ in the PCI group and $22.7 \%$ in the CABG group. However, among the subgroup of patients with treated diabetes $(\mathrm{n}=$ 353), CABG had a long-term benefit over PCI, based on reduced cardiac mortality in the patients undergoing CABG, with mortality rates of PCI versus CABG of $54.5 \%$ versus $42.1 \%$, respectively [26]. The recent meta-analysis by Hlatky et al (2009) showed that in 10 trials with 7,812 patients confirmed the long-term benefit of CABG [27]. In the 1,233 patients with diabetes the 5-year mortality rate was significantly lower with $12.3 \%$ in the CABG group versus $20.0 \%$ in the PCI group. In the recent Bypass Angioplasty Revascularization Investigation 2 Diabetes (BARI 2D) (2009) with 2368 type 2 diabetes patients the absolute rates of major adverse cardiac events were equal in patients treated with PCI $(n=798)$ or CABG $(n=378)$, i.e. $23 \%$ versus $22.4 \%$ [28]. In the BARI 2D both BMS and DES were used.

Drug eluting stents versus coronary artery bypass grafting Conversely, when comparing DES with CABG for multivessel disease, the Synergy between PCI with Taxus and 
Cardiac Surgery (SYNTAX) trial by Serruys et al (2009) with 1800 patients showed that the rates of myocardial infarction and mortality were similar between PCI and CABG groups [29]. Major adverse cardiac and cerebrovascular events (MACCE) were significantly increased in the PCI group, mainly due to higher rates of revascularization. In the SYNTAX patients with more severe coronary artery disease, and especially those with diabetes, CABG was related to a higher freedom from re-intervention. These results were corroborated by Tarantini et al (2009), Daemen et al (2008), Briguori et al (2007) and Lee et al (2007), respectively including 220, 159, 218 and 205 diabetics [30-33].

\section{Antiplatelet Agents Thienopyridines}

Insulin resistance leads to upregulation of the P2Y-receptor-pathway, a platelet membrane protein [15]. The P2Yreceptor is the target of the active metabolite of clopidogrel. Post-PCI this results in increased platelet reactivity in diabetics [15]. Therefore, a higher dose of thienopyridines seems needed in diabetics to attain an adequate antithrombotic regiment [34]. Illustrating the importance of antithrombotic therapy in diabetics, Stettler et al (2009) demonstrated that, in contrast to non-diabetics, drug eluting stents in diabetics are only safe to use if adequate antiplatelet therapy is administered [21]. Wiviott et al (2008) demonstrated in 3,146 patients with diabetes that prasugrel compared with clopidogrel leads to a reduction in cardiovascular death, MI and stroke $(12.2 \%$ versus $17 \%$ ) [35]. This illustrates the potential to overcome the relative antiplatelet drug resistance of diabetes with novel pharmacologic agents.

\section{Glycoprotein IIb/IIla receptor blockade}

During PCI both profound vessel wall injury and plaque rupture occur. This triggers activation of the coagulation cascade, and adhesion, activation and aggregation of platelets. Platelets express more glycoprotein (GP) IIb/IIIa receptors in diabetics and have a tendency to aggregate, especially in the presence of hyperglycemia $[1,36]$. Type 2 diabetics on insulin have greater platelet aggregation than type 2 diabetics non treated with insulin [36]. Labinaz et al (2002) compared GP IIb/IIIa receptor blockers in PCIs in diabetics $(n=466)$ and non-diabetics $(n=1,595)$ [37]. The group of patients receiving GP IIb/IIIa receptor blockers had significant decreased rates of mortality, TVR and MI. However, the relative risk reduction for diabetics was similar to the reduction in non-diabetics.

\section{Glucose Lowering Agents and Restenosis}

The effect of treatment with glucose lowering agents on macrovascular disease is not well established. In the European Heart Survey a pronounced decrease in cardiovascular events in patients with newly detected diabetes prescribed glucose lowering agents compared with those not receiving such treatment was observed [38]. Several retrospective analyses of databases showed differences in coronary revascularization and $\mathrm{MI}$ in patients treated with different regimens (table 2). The major recognized limitation of these analyses is the bias of patients with a higher risk profile treated with insulin or combination therapy [39]. The above-mentioned BARI 2D also showed that after a follow-up period of more than 3 years in patients treated with PCI that no survival benefit could be observed between patients treated with metformin or TZDs (insulin sensitization, 10.2\%) as compared to insulin or sulfonylurea (insulin provision, 11.4\%) [28]. However, the rate of major cardiovascular events was 3.8\% lower in the insulin sensitization group treated with PCI, albeit non-significant. The effect of the individual glucose lowering agents was not reported (yet). The effect of glucose lowering, i.e. more strict versus moderate glucose control, on outcome has been extensively investigated. In a meta-analysis (2009) of 5 large trials the rate of nonfatal myocardial infarction was significantly lower in the stricter compared to the moderate glucose control group, $10.0 \%$ versus $12.3 \%$ [40]. Whether strict glucose control, irrespective of specific glucose lowering agents, is related to a reduction of restenosis is not known.

\section{Thiazolidinediones}

Thiazolidinediones (TZDs) are peroxisome proliferator activated receptors (PPAR)-gamma agonists. They decrease insulin resistance, levels of CRP, fibrinogen, LDL-cholesterol, triglycerides and resistin in comparison with placebo $[17,41]$. TZDs inhibit VSMC proliferation, ameliorating intimal hyperplasia and restenosis [42]. Under high glucose conditions the inhibitory activity of VSMC proliferation by pioglitazone and rosiglitazone is enhanced, in contract to troglitazone [42].

Several studies have suggested the preventive effects of TZDs on atherosclerosis, restenosis, in-stent restenosis, and reocclusion after PCI in patients with type 2 diabetes.

Table 2: Elevated $(\uparrow)$ or decreased $(\downarrow)$ risk of restenosis, target laesion vascularization (TLR), death or myocardial infarction (MI) of the different groups of glucose lowering agents after $\mathrm{PCl}$.

Risk Modulation of Glucose Lowering Agents in Diabetics After PCl

\begin{tabular}{llcll}
\hline Agent & Restenosis & TLR & Death & MI \\
\hline TZDs & $\downarrow$ & $\downarrow$ & $\downarrow$ & - \\
\hline Sulfonylurea & $\uparrow$ & - & $\uparrow$ & - \\
\hline Biguanides & - & $\downarrow$ & - & $\downarrow$ \\
\hline Insulin & $\uparrow$ & $\uparrow$ & $\uparrow$ & $\uparrow$ \\
\hline
\end{tabular}


Takagi et al (2002) showed in a randomized study that in 55 patients with 60 lesions troglitazone was associated with reduced angiographic in-stent restenosis and neointimal tissue proliferation [43]. Choi et al (2004) found in a case-control study with 83 patients treated with rosiglitazone that at 6 months a significant reduction in restenosis rate, greater minimal lumen stent diameter and albeit non-significant lower TVR [44]. Nishio et al (2006) observed in randomized study with 54 patients that treatment with pioglitazone attenuated neointimal thickening regardless of the type of PCI and resulted in less late luminal loss [45]. The meta-analysis of Rosmarakis et al in 2007 already showed that TZDs decrease the need for target vessel revascularization when 5 trials with 235 patients were analyzed [46]. The meta-analysis by Geng et al published in 2009 consisted of 8 trials with 366 patients and showed that TZDs were associated with a significant reduction in the risk of in-stent restenosis in both diabetic and non-diabetic patients [47]. They also observed a reduction in late lumen loss, percent diameter stenosis, neointimal area/volume, and target lesion revascularization. Recently, Finn et al (2009) randomly assigned 65 diabetics to rosiglitazone or placebo and could not confirm the above described results on luminal loss [48]. An interesting observation was made by Nishio et al (2006), i.e. that in 38 type 2 diabetics similar restenosis rates were present in patients treated with either a BMS with pioglitazone or sirolimus-eluting stent without pioglitazone [49]. Fang et al (2007) demonstrated that rosiglitazone therapy in comparison to standard antidiabetic therapy without rosiglitazone in type 2 diabetics leads to a significant decrease in restenosis and mortality [50]. However, the intervention group significantly used more insulin and biguanides, which might lead to bias of the observed effects. In a study with 417 patients referred for stress testing to evaluate chest pain by Kapinya et al (2008), 222 were treated with conventional therapy only (insulin and insulin secretagogues) and 195 as being treated with insulin sensitizers (metformin and thiazolidinediones) [51]. The rate of ischemia and MI was not significantly lower in patients treated with thiazolidinediones. In the Pioglitazone Effect on Regression of Intravascular Sonographic Coronary Obstruction Prospective Evaluation (PERISCOPE)-trial, Nissen et al (2008) demonstrated that in patients with type 2 diabetes and coronary artery disease treatment with pioglitazone compared with glimepiride results in a significantly lower rate of progression of coronary atherosclerosis, as measured with intravascular ultrasound [52]. The patients receiving pioglitazone also had significantly reduced levels of CRP, triglycerides and HbA1c and an increase in HDL. Nonetheless, this trial did not show any significant differences in clinical outcome between pioglitazone and glimepiride. Recently, Clementi et al (2009) demonstrated in 25 patients with diabetes that administration of pioglitazone combined with atorvastatin leads to a significant regression of coronary atherosclerosis [53].

\section{Biguanides}

The precise mechanism of action of biguanides, i.e. metformin, is not completely elucidated. Metformin has insulin sensitizing effects, and may therefore have cardiovascular effects [54]. In the previously described study by Kapinya et al (2004), only the 125 patients on metformin had lower rates of ischemia and MI [51]. In diabetics undergoing PCI, Kao et al (2004) showed that metformin-therapy in comparison with insulin and sulfonylurea was associated with a reduced risk of MI and mortality [54]. It is not clear whether the superiority of metformin therapy in this trial is due to beneficial effects of the metformin or is due to possible adverse effects of the sulfonylurea on atherosclerosis. In the study by Walker et al (2008) it was observed that patients treated with metformin were less likely to need revascularization or suffer from MI compared to other treatment regimens [39]. Comparable results were observed by Casscells et al with 232,000 diabetics (2008) [55]. On the other hand in a post-hoc analysis of the Diabetes and Insulin-Glucose Infusion in Acute Myocardial Infarction (DIGAMI)-2 trial with 1181 patients no differences on cardiovascular mortality were observed, although metformin was associated with a significant lower rate of non-fatal MI and stroke as compared to sulfonylurea or insulin treatment [56].

Adversely, metformin therapy may also lead to progression of coronary artery disease. Chronic use of metformin leads to decreased intestinal absorption of group B vitamins and folate. These deficiencies lead to elevated levels of homocysteine, which accelerates progression of cardiovascular disease due to adverse effects on platelets, endothelium and clothing factors [57].

\section{Sulfonylurea}

Sulfonylurea act through binding to the sulfonylurea receptor on the surface of pancreatic $\beta$ cells. This results in closure of the potassium channels and thereby depolarization of the cell membrane and, in turn, opening of voltage-dependent calcium channels. The influx of calcium causes microtubules to contract and the exocytosis of insulin from vesicles. Garratt et al (1999) report that sulfonylurea drugs are associated with an increased risk of inhospital mortality among 185 diabetic patients undergoing angioplasty for acute myocardial infarction [58]. No association between sulfonylurea drugs and late adverse events after primary PCI has been observed. The explanation for this early risk is not an increase in ventricular arrhythmias, but reflects the deleterious effects of sulfonylurea drugs on myocardial tolerance for ischemia and reperfusion. Blockade of K-ATP-channels, which is the target of sulfonylurea drugs, promotes insulin release in pan- 
creatic B-cells, but also affects in certain sulfonylurea drugs cardiac tissue and coronary arteries [59]. This leads to greater vulnerability of the myocardium to ischemia, which results in the increased clinical manifestations of ischemia $[57,60]$.

Sulfonylurea drug use lead to elevated IL-12 serum levels in type-2 diabetics, induced by peripheral insulin resistance and beta cell dysfunction, as expressed by fasting serum proinsulin levels. Therefore, according to the hypothesis by Wegner et al, sulfonylurea drugs can promote atherosclerosis [14].

\section{Insulin}

Huang et al demonstrated that high levels of insulin are potent in stimulating VSMC proliferation [61]. The clinical relevance of this observation has yet to be investigated. In all the above-described studies patients treated with insulin had higher rates of either ischemia or infarction.

\section{Conclusion}

Diabetes is a major risk factor for adverse events after PCI. Diabetics have higher rates of mortality, myocardial infarction and target vessel revascularisation than non-diabetics. Recent therapeutical antithrombotic and percutaneous developments improved the prognosis both for diabetics and non-diabetics, thereby maintaining a worse prognosis for diabetics.

The exact mechanism of restenosis is not yet completely understood, although several contributing factors have been identified. Several glucose lowering drugs influence the restenosis process. Current data of especially metformin and thiazolidinediones indicate beneficial results as compared with insulin and sulfonylurea. However, no large prospective trials in which the clinical impact of these drugs on restenosis is investigated have been undertaken.

The prognosis of diabetics undergoing PCI remains worse than non-diabetics. Possibly the best way to improve the prognosis of diabetics undergoing PCI is to prevent diabetes or to pursue adequate diabetes regulation.

\section{Future area of interest}

Due to the negative influence of diabetes on prognosis after PCI, glucose lowering therapy might have a substantial influence on coronary restenosis and the worse prognosis of diabetics. Future studies might determine whether or not the type of glucose lowering agent has influence on restenosis after PCI.

\section{Competing interests}

The authors declare that they have no competing interests.

\section{Authors' contributions}

The authors responsibilities were as follows - CL: study design, data interpretation, data collection and drafting the manuscript; BR and IH: study design, data interpretation and critical revision of the manuscript for important intellectual content; JM and FZ: study design and critical revision of the manuscript for important intellectual content. All authors approved the final manuscript.

\section{References}

I. Flaherty JD, Davidson C): Diabetes and coronary revascularisation. JAMA 2005, 293:150I-I508.

2. Huxley R, Barzi F, Woodward M: Excess risk of fatal coronary heart disease associated with diabetes in men and women: meta-analysis of 37 prospective cohort studies. BMJ 2006, 332:73-78.

3. Mosseri M, Nahir M, Rozenman Y, Lotan C, Admon D, Raz I, Gotsman MS: Diffuse narrowing of coronary arteries in diabetic patients: the earliest phase of coronary artery disease. Cardiology 1998, 89: 103-II0.

4. Dortimer AC, Shenoy PN, Shiroff RA, Leaman DM, Babb JD, Liedtke AJ, Zelis R: Diffuse coronary artery disease in diabetic patients: fact or fiction? Circulation 1978, 57:133-136.

5. Abaci A, Oğuzhan A, Kahraman S, Eryol NK, Unal S, Arinç H, Ergin A: Effects of diabetes mellitus on formation of coronary collateral vessels. Circulation 1999, 99:2239-2242.

6. Burke AP, Kolodgie FD, Zieske A, Fowler DR, Weber DK, Varghese PJ, Farb A, Virmani R: Morphologic findings of coronary atherosclerotic plaques in diabetics: a postmortem study. Arterioscler Thromb Vasc Biol 2004, 24: I 266-I 271.

7. Moreno PR, Fuster V: New Aspects in the pathogenesis of diabetic atherothrombosis. J Am Coll Cardiol 2004, 44:2293-2300.

8. Nicholls S), Tuzcu EM, Kalidindi S, Wolski K, Moon KW, Sipahi I, Schoenhagen P, Nissen SE: Effect of diabetes on progression of coronary atherosclerosis and arterial remodeling: a pooled analysis of $\mathbf{5}$ intravascular ultrasound trials. I Am Coll Cardiol 2008, 52:255-262.

9. Gruentzig A: Transluminal dilatation of coronary artery stenosis (letter). Lancet 1978, I:263.

10. Airoldi F, Briguori C, lakovou I, Stankovic G, Biondi-Zoccai G, Carlino M, Chieffo A, Montorfano M, Cosgrave J, Michev I, Rogacka R, Sangiorgi GM, Colombo A: Comparison of sirolimus versus paclitaxel eluting stents for treatment of coronary in-stent restenosis. Am J Cardiol 2006, 97: I I82-I I87.

II. Moreno PR, Murcia AM, Palacios IF, Leon MN, Bernardi VH, Fuster V, Fallon JT: Coronary composition and macrophage infiltration in atherectomy specimens from patients with diabetes mellitus. Circulation 2000, 102:2180-2184.

12. Faries PL, Rohan DI, Takahara H, Wyers MC, Contreras MA, Quist WC, King GL, Logerfo FW: Human vascular smooth muscle cells of diabetic origin exhibit increased proliferation, adhesion and migration. J Vasc Surg 200I, 33:60I-607.

13. Expert Panel on Detection, Evaluation, and Treatment of High Blood Cholesterol in Adults: Executive summary of the third report of the national cholesterol education program (NCEP) expert panel on detection, evaluation, and treatment of high blood cholesterol in adults (adult treatment panel III). JAMA 200I, 285:2486-2497.

14. Wegner M, Winiarska H, Bobkiewicz-Kozłowska T, Dworacka M: IL12 serum levels in patients with type 2 diabetes treated with sulphonylureas. Cytokine 2008, 42:312-316.

15. van Werkum JW, Heestermans AA, Plokker HW, ten Berg JM: Clinical, biochemical and genetical resistance to clopidogrel in a patient with recurrent stent thrombosis. Int J Cardiol 2007, 116:136-137.

16. Walcher D, Babiak C, Poletek P, Rosenkranz S, Bach H, Betz S, Durst R, Grüb M, Hombach V, Strong J, Marx N: C-peptide induces vascular smooth muscle cell proliferation; involvement of SrcKinase, Phosphatidylinositol 3-Kinase, and Extracellular Signal-Regulated Kinase 1/2. Circ Res 2006, 99:I I8I-I I87.

17. Calabro P, Samudio I, Willerson JT, Yeh ET: Resistin promotes smooth muscle cell proliferation through activation of extra- 
cellular signal regulated kinase $\mathbf{I} / \mathbf{2}$ and phosphatidfylinositol 3-kinase pathways. Circulation 2004, I I 0:3335-3340.

18. On YK, Park HK, Hyon MS, Jeon ES: Serum resistin as a biological marker for coronary artery disease and restenosis in type 2 diabetic patients. Circ J 2007, 71:868-873.

19. Serruys PW, de Jaegere P, Kiemeneij F, Macaya C, Rutsch W, Heyndrickx G, Emanuelsson H, Marco J, Legrand V, Materne P, Belardi J, Sigwart U, Colombo A, Goy J], Heuvel P van den, Delcan J, Morel MA A comparison of balloon-expandable-stent implantation with balloon angioplasty in patients with coronary artery disease. Benestent Study Group. N Engl J Med 1994, 33 I:489-495.

20. Haude M, Erbel R, Issa H, Meyer J: Quantitative analysis of elastic recoil after balloon angioplasty and after intracoronary implantation of balloon-expandable Palmaz-Schatz stents. am Coll Cardiol 2002, 39:183-193.

21. Stettler C, Alleman S, Wandel S, Kastrati A, Morice MC, Schömig A, Pfisterer ME, Stone GW, Leon MB, de Lezo JS, Goy J], Park SJ, Sabaté M, Suttorp MJ, Kelbaek H, Spaulding C, Menichelli M, Vermeersch P, Dirksen MT, Cervinka P, De Carlo M, Erglis A, Chechi T, Ortolani P, Schalij MJ, Diem P, Meier B, Windecker S, Jüni P: Drug eluting and bare metal stents in people with and without diabetes: collaborative network meta-analysis. BMJ 2008, 29:a I33I.

22. Jensen LO, Maeng M, Mintz GS, Christiansen EH, Hansen KN, Galloe A, Kelbaek H, Lassen JF, Thuesen L, Thayssen P: Serial intravascular ultrasound analysis of peri-stent remodeling and proximal and distal edge effects after sirolimus-eluting or paclitaxel-eluting stent implantation in patients with diabetes mellitus. Am J Cardiol 2009, 103:1083-1088.

23. Fröbert $O$, Lagerqvist B, Carlsson J, Lindbäck J, Stenestrand U, James SK: Differences in restenosis rate with different drug-eluting stens in patients with and without diabetes mellitus. J Am Coll Cardiol 2009, 53:1660-1667.

24. Lee SW, Park SW, Kim YH, Yun SC, Park DW, Lee CW, Hong MK, Rhee KS, Chae JK, Ko JK, Park JH, Lee JH, Choi SW, Jeong JO, Seong IW, Cho YH, Lee NH, Kim JH, Chun KJ, Kim HS, Park SJ: A randomized comparison of sirolimus- versus paclitaxel-eluting stent implantation in patients with diabetes mellitus: 2-year clinical outcomes of the DES-DIABETES trial. J Am Coll Cardiol 2009, 53:812-8I3.

25. Schömig A, Dibra A, Windecker S, Mehilli J, Suárez de Lezo J, Kaiser C, Park SJ, Goy JJ, Lee JH, Di Lorenzo E, Wu J, Jüni P, Pfisterer ME, Meier B, Kastrati A: A meta-analysis of 16 randomized trials of sirolimus-eluting versus paclitaxel-eluting stents in patients with coronary artery disease. J Am Coll Cardiol 2007, 50:1373-I380.

26. The BARI investigators: The final I 0 -year follow-up results from the BARI randomized trial. J Am Coll Cardiol 2007, 49:1600-1606

27. Hlatky MA, Boothroyd DB, Bravata DM, Boersma E, Booth J, Brooks MM, Carrie D, Clayton TC, Danchin N, Flatcher M, Hamm CW, Hueb WA, Kähler J, Kelsy SF, King SB, Kosinki AS, Lopes N, McDonald KM, Rodriguez A, Serruys P, Sigwart U, Stables RH, Owens DK, Pocock S): Coronary artery bypass surgery compared with percutaneous coronary interventions for multivessel disease: a collaborative analysis of individual patient data from ten randomised trials. Lancet 2009, 373: I190-II97.

28. BARI 2D Study Group, Frye RL, August P, Brooks MM, Hardison RM, Kelsy SF, MacGregor JM, Orchard TJ, Chaitman BR, Genuth SM, Goldberg SH, Hlatky MA, Jones TL, Molitch ME, Nesto RW, Sako EY, Sobel BE: A randomized trial of therapies for type 2 diabetes and coronary artery disease. N EnglJ Med 2009, 360:2503-25I5.

29. Serruys PW, Morice MC, Kappetein P, Colombo A, Holmes DR, Mack MJ, Ståhle E, Feldman TE, Brand M van den, Bass EJ, Van Dyck N, Leadley K, Dawkins KD, Mohr FW: Percutaneous coronary intervention versus coronary-artery bypass grafting for severe coronary artery disease. N Engl J Med 2009, 360:96I-972.

30. Tarantini G, Ramondo A, Napodano M, Favaretto E, Gardin A, Bilato C. Nesseris G, Tarzia V, Cademartiri F, Gerosa G, lliceto S: PCI versus CABG for multivessel coronary disease in diabetics. Catheter Cardiovasc Interv 2009, 73:50-8.

3I. Daemen J, Kuck KH, Macaya C, Legrand V, Vrolix M, Carrie D, Sheiban I, Suttorp MJ, Vranckx P, Rademaker T, Goedhart D, Schuijer M, Wittebols K, Macours N, Stoll HP, Serruys PW: Multivessel coronary revascularization in patients with and without diabetes mellitus. J Am Coll Cardiol 2008, 52:1957-1967.

32. Briguori C, Condorelli G, Airoldi F, Focaccio A, D'Andrea D, Cannavale M, Abarghouei AA, Giordano S, De Vivo F, Ricciardelli B,
Colombo A: Comparison of coronary drug-eluting stents versus coronary artery bypass grafting in patients with diabetes mellitus. Am J Cardiol 2007, 99:779-784.

33. Lee MS, Jamal F, Kedia G, Chang G, Kapoor N, Forrester J, Czer L, Zimmer R, DeRobertis M, trento A, Makker RR: Comparison of bypass surgery with drug-eluting stents for diabetic patients with multivessel disease. Int I Cardiol 2007, I 23:34-42.

34. Angiolillo DJ, Shoemaker SB, Desai B, Yuan H, Charlton RK, Bernardo E, Zenni MM, Guzman LA, Bass TA, Costa MA: Randomized comparison of a high clopidogrel maintenance dose in patients with diabetes mellitus and coronary artery disease: results of the optimizing antiplatelet therapy in diabetes mellitus (OPTIMUS) study. Circulation 2007, I I 5: I-9.

35. Wiviott SD, Braunwald E, Angiolillo DJ, Meisel S, Dalby AJ, Verheugt FW, Goodman SG, Corbalan R, Purdy DA, Murphy SA, McCabe CH, Antman EM: Greater clinical benefit of more intensive oral antiplatelet therapy with prasugrel in patients with diabetes mellitus in the trial to assess improvement in therapeutic outcomes by optimizing platelet inhibition with prasugrelthrombolysis in myocardial infarction 38. Circulation 2008, I 1 8:1626-1636.

36. Angiolillo DJ, Bernardo E, Ramirez C, Costa MA, Sabaté M, JimenezQuevedo P, Hernández R, Moreno R, Escaned J, Alfonso F, Banuelos C, Bass TA, Macaya C, Fernandez-Ortiz A, et al.: Insulin therapy is associated with platelet dysfunction in patients with type 2 diabetes mellitus on dual oral antiplatelet treatment. J Am Coll Cardiol 2006, 48:298-304.

37. Labinaz M, Madan M, O'Shea JO, Kilaru R, Chin W, Pieper K, McGuire DK, Sucedo JF, Talley JD, Lui H, Kitt MM, Califf RM, Tcheng JT: Comparison of one-year outcomes following coronary artery stenting in diabetic versus non-diabetic patients (from the enhanced suppression of the platelet IIb/IIla receptor with integrilin therapy [ESPRIT] trial). Am J Cardiol 2002, 90:585-590.

38. Anselmino M, Ohrvik J, Malmberg K, Standl E, Rydén L: Glucose lowering treatment in patients with coronary artery disease is prognostically important not only in established but also in newly detected diabetes mellitus: a report from the Euro Heart Survey on Diabetes and the Heart. Eur Heart J 2008, 29:177-I84.

39. Walker AM, Koro CE, Landon J: Coronary heart disease outcomes in patients receiving antidiabetic agents in the PharMetrics database 2000-2007. Pharmacoepidemiol Drug Saf 2008, I7:760-768.

40. Ray KK, Seshasai SR, Wijesuriya S, Sivakumaran R, Nethercott S, Preiss $D$, Erquo $S$, Sattar N: Effect of intensive control of glucose on cardiovascular outcomes and death in patients with diabetes mellitus: a meta-analysis of randomised controlled trials. Lancet 2009, 373:1765-1772

4I. Sidhu JS, Cowan D, Kaski JC: The effects of rosiglitazone, a peroxisome proliferator-activated receptorgamma agonist, on markers of endothelial cell activation, C-reactive protein and fibrinogen levels in non-diabetic coronary artery disease patients. J Am Coll Cardiol 2003, 42: 1757-I763.

42. Little PJ, Osman N, de Dios ST, Cemerlang N, Ballinger M, Nigro J: Anti-proliferative activity of oral anti-hyperglycemic agents on human vascular smooth muscle cells: thiazolidinediones (glitazones) have enhanced activity under high glucose conditions. Cardiovasc Diabetol 2007, 6:33.

43. Takagi T, Yamamuro A, Tamita K, Yamabe K, Katayama M, Morioka $\mathrm{S}$, Akasaka T, Yoshida K: Impact of troglitazone on coronary stent implantation using small stents in patients with type 2 diabetes mellitus. Am J Cardiol 2002, 89:3 I8-322.

44. Choi D, Kim SK, Choi SH, Ko YG, Ahn CW, Jang Y, Lim SK, Lee HC Cha BS: Preventive effects on rosiglitazone on restenosis after coronary stent implantation in patients with type 2 diabetes. Diabetes Care 2004, 27:2654-2660.

45. Nishio K, Sakurai M, Kusuyama T, Shigemitsu M, Fukui T, Kawamura $\mathrm{K}$, Itoh S, Konno N, Katagiri T: A randomized comparison of pioglitazone to inhibit restenosis after coronary stenting in patients with type 2 diabetes. Diabetes Care 2006, 29:10I-106.

46. Rosmarakis ES, Falagas ME: Effect of thiazolidinedione therapy on restenosis after coronary stent implantation: a metaanalysis of randomized controlled trials. Am Heart J 2007, 154:144-150. 
47. Geng DF, Jin DM, Wu W, Wang Z, Wang JF: Effect of thiazolidinediones on in-stent restenosis in patients after coronary stenting: a meta-analysis of randomized controlled trials. Atherosclerosis 2009, 202:52I-528.

48. Finn AV, Oh JS, Hendricks M, Daher M, Cagliero E, Byrne RM, Nadelson J, Crimins J, Kastrati A, Schömig A, Bruskina O, Palacios I, John MC, Gold HK: Predictive factors for in-stent late loss and coronary lesion progression in patients with type 2 diabetes mellitus randomized to rosiglitazone or placebo. Am Heart J 2009, 157:383-388.

49. Nishio K, Shigemitsu M, Kodama Y, Konno N, Katagiri T, Kobayashi $Y$ : Comparison of bare metal stent with pioglitazone versus sirolimus-eluting stent for percutaneous coronary intervention in patients with type 2 diabetes mellitus. Cardiovasc Revasc Med 2009, I 0:5-II.

50. Fang CC, Ng Yao YT, Yi-Chen, Yu CL, Chen CL, Wang SP: Angiographic and clinical outcomes of rosiglitazone in patients with type 2 diabetes mellitus after percutaneous coronary interventions: a single center experience. Angiology 2007, 58:523-534.

51. Kapinya K, Nijjar PS, Stanek M, Amanullah A: Insulin-sensitizing antihyperglycaemic medications are associated with better outcome in patients with diabetes undergoing cardiac stress testing. Intern Med J 2008, 38:259-264.

52. Nissen SE, Nicholls SJ, Wolski K, Nesto R, Kupfer S, Perez A, Jure H, De Larochellière R, Staniloae CS, Mavromatis K, Saw J, Hu B, Lincoff AM, Tuzcu EM: Comparison of pioglitazone vs glimepiride on progression of coronary atherosclerosis in patients with type 2 diabetes: the PERISCOPE randomized controlled trial. JAMA 2008, 299:156I-I573.

53. Clementi F, Di Luozzo M, Mango R, Luciani G, Trivisonno A, Pizzuto F, Martuscelli F, Mehta JL, Romeo F: Regression and shift in composition of coronary atherosclerotic plaques by pioglitazone: insight from an intravascular ultrasound analysis. J Cardiovasc Med 2008, 10:23I-237.

54. Kao J, Tobis J, McClelland RL, Heaton MR, Davis BR, Holmes DR Jr, Currier JW: Relation of metformin treatment to clinical events in diabetic patients undergoing percutaneous intervention. Am J Cardiol 2004, 93: I 347-1350.

55. Casscells SW, Granger E, Swedorske J, Goldhammer R, Shaheen M, Dorris J, Hong A, Wiktor M: A comparison of select cardiovascular outcomes by antidiabetic prescription drug classes used to treat type 2 diabetes among Military Health System beneficiaries, fiscal year 2003-2006. Am J Ther 2008, 15:198-205.

56. Melbin LG, Malmberg K, Norhammar A, Wedel H, Rydén L: The impact of glucose lowering treatment on long-term prognosis in patients with type 2 diabetes and myocardial infarction: a report from the DIGAMI 2 trial. Eur Heart J 2008, 29: I 66- 176.

57. Fisman EZ, Motro M, Tenenbaum A: Non-insulin antidiabetic therapy: current problems and future prospects. Adv Cardiol 2008, 45:154-I70.

58. Garratt KN, Brady PA, Hassinger NL, Grill DE, Terzic A, Holmes DR Jr: Sulfonylurea drugs increase early mortality in patients with diabetes mellitus after direct angioplasty for acute myocardial infarction. I Am Coll Cardiol 1999, 33:119-124.

59. Fosset M, De Weille JR, Green RD, Schmid-Antomarchi H, Lazdunski $M$ : Antidiabetic sulphonylureas control action potential properties in heart cells via high affinity receptors that are linked to ATP-dependent $\mathbf{K}+$ channels. J Biol Chem 1988, 263:7933-7936.

60. Tomai F, Crea F, Gaspardone A, Versaci F, De Paulis R, Renta a Peppo A, Chiariello L, Gioffrè PA: Ischemic preconditioning during coronary angioplasty is prevented by glibenclamide, a selective ATP-sensitive K+ channel blocker. Circulation 1994, 90:700-705.

61. Huang B, Dreyer T, Heidt M, Yu JC, Philipp M, Hehrlein FW, Katz N, Al-Fakhri N: Insulin and local growth factor PDGF induce intimal hyperplasia in bypass graft culture models of saphenous vein and internal mammary artery. Eur J Cardiothorac Surg 2002 21:1002-1008.
Publish with Bio Med Central and every scientist can read your work free of charge

"BioMed Central will be the most significant development for disseminating the results of biomedical research in our lifetime. "

Sir Paul Nurse, Cancer Research UK

Your research papers will be:

- available free of charge to the entire biomedical community

- peer reviewed and published immediately upon acceptance

- cited in PubMed and archived on PubMed Central

- yours - you keep the copyright

Submit your manuscript here:

http://www.biomedcentral.com/info/publishing_adv.asp
BioMedcentral 